\title{
Healing through language: Positive physical health effects of
}

\section{indigenous language use [version 1; peer review: 2 approved}

\section{with reservations]}

\section{H. Whalen ${ }^{1-4}$, Margaret Moss ${ }^{5}$, Daryl Baldwin ${ }^{6}$}

${ }^{1}$ Endangered Language Fund, New Haven, CT, USA

${ }^{2}$ Speech-Language-Hearing Sciences, Graduate Center, City University of New York, New York, NY, USA

${ }^{3}$ Haskins Laboratories, New Haven, CT, USA

${ }^{4}$ Linguistics, Yale University, New Haven, CT, USA

5 School of Nursing, University of Buffalo, Buffalo, NY, USA

${ }^{6}$ The Myaamia Center, Miami University, Oxford, OH, USA

V1 First published: 09 May 2016, 5:852

https://doi.org/10.12688/f1000research.8656.1

Latest published: 09 May 2016, 5:852

https://doi.org/10.12688/f1000research.8656.1

\section{Abstract}

This article summarizes existing work that indicates language maintenance and revitalization efforts result in health-related benefits for Native Americans and other indigenous populations. Although forced loss of ancestral language has been a feature of life in most indigenous communities since the first contact with Europeans, the pace of loss has accelerated in the past 50 years. Among the many hardships such communities face, an especially troubling one is lowered health status. There are indications, however, that language maintenance and revitalization efforts have positive effects on physical and communal health among indigenous populations. The types of language programs currently in place are outlined along with a variety of studies that will measure health improvement outcomes correlated with language revitalization efforts. Such evidence justifies increased support for language revitalization in order to improve health.

\section{Keywords}

indigenous health, social determinants of health, language, Native American, resilience, revitalization, community

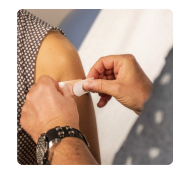

This article is included in the Sociology of Health gateway.

\section{Open Peer Review}

\begin{tabular}{ccc} 
Approval Status & $? ?$ \\
& 1 & 2 \\
\hline version 1 & $?$ & $?$ \\
09 May 2016 & view & view
\end{tabular}

1. Richard T Oster, University of Alberta, Edmonton, Canada

\section{Terryann Coralie Clark, University of \\ Auckland, Auckland, New Zealand}

Any reports and responses or comments on the article can be found at the end of the article. 
Corresponding author: D. H. Whalen (whalen@haskins.yale.edu)

Competing interests: No competing interests were disclosed.

Grant information: The author(s) declared that no grants were involved in supporting this work.

Copyright: $\odot 2016$ Whalen DH et al. This is an open access article distributed under the terms of the Creative Commons Attribution License, which permits unrestricted use, distribution, and reproduction in any medium, provided the original work is properly cited.

How to cite this article: Whalen $\mathrm{DH}$, Moss $\mathrm{M}$ and Baldwin $\mathrm{D}$. Healing through language: Positive physical health effects of indigenous language use [version 1; peer review: 2 approved with reservations] F1000Research 2016, 5:852

https://doi.org/10.12688/f1000research.8656.1

First published: 09 May 2016, 5:852 https://doi.org/10.12688/f1000research.8656.1 


\section{Introduction}

Indigenous communities have some of the worst health outcomes within their larger societies (Gracey \& King, 2009). This is true across the world, for example, in Australia and New Zealand (Anderson et al., 2006), Latin America (Pan American Health Organization, 2001), Canada (Frohlich et al., 2006), and the United States (U.S. Commission on Civil Rights, 2004). Although many factors, such as location, poverty, and access to health facilities, contribute to this disparity, there is a growing recognition that historical trauma plays a role as well (Duran et al., 1998; Sotero, 2006). The present survey examines published studies that address one salient means of recovering from historical trauma, namely, maintenance and revitalization of indigenous language. These studies consistently find that there are physical health advantages to be gained from such efforts.

The ways in which languages emerge, evolve, and fall dormant have been increasingly discussed by linguists, biologists and cognitive scientists in the last two decades (Hale et al., 1992; Wang \& Minett, 2005). However, health scientists have not largely embraced this discussion as relevant. Although native language is sometimes mentioned in "health literacy" (e.g. Berkman et al., 2011), health related outcomes as a result of language maintenance and revitalization efforts have not received much attention. Here, we explore the limited existing literature on health outcomes of indigenous language use and outline promising research avenues for the future.

Language is a uniquely efficient means of maintaining and passing on crucial cultural knowledge and thus promotes cultural diversity (McCarty \& Zepeda, 2010). Although languages have come and gone throughout history, indigenous languages in a variety of postcolonial situations have been oppressed through official policies and social pressures (Dussias, 1999; Oster et al., 2014). These forced language shifts caused the loss of social and behavioral knowledge and understanding that was created over millennia, ultimately contributing to disastrous, endemic health deficits (Gracey \& King, 2009; Hallett et al., 2007; King et al., 2009).

Emerging evidence (see "Existing studies" section below) ties individual and/or communal health to efforts that promote ancestral language and cultural fluency in a community-driven educational environment. Some of the literature addresses indigenous groups affected by the four settler states of the United States (US), Canada, New Zealand and Australia. The similarities in colonialism, history and outcomes for the original peoples outweigh the inevitable differences in specific situations. Further, the political boundaries between Canada and the US do not reflect original use and are often unrecognized by the first peoples. Here, indigenous people of North America (hereafter, called Native Americans or (NA)) will be an exemplar as we explore the ability to use one's ancestral language as a knowledge-seeking catalyst to optimize health.

\section{Health status}

Native Americans suffer some of the poorest health statuses and health outcomes of any other racial group in the US (Indian Health Service, 2014). This includes shorter lifespans, higher death rates from a wide variety of causes, and more limited access to health services. According to the 2010 American Community Survey, NA have a higher rate of disability than any other single group at $15 \%$, almost 25\% higher than for whites. While some of this is due to rural poverty, disparities are profound even within urban areas (as reported for Canada) (Firestone et al., 2014).

Current, low socio-economic status clearly is a major factor for poor health outcomes in NAs, but NA health today also results from historical trauma and its inter-generational continuation. Federal Indian Policies from 200 years of removal, reservations, relocation/ assimilation, termination, and language eradication have resulted in loss of identity, shame, guilt, unresolved grief and depression (Brave Heart \& DeBruyn, 1998; Oster et al., 2014), key features of historical trauma. In today's Native America, extreme poverty, poor health, and high homicide and suicide rates are tragic outcomes of this historical trauma (Brave Heart \& DeBruyn, 1998; Sotero, 2006).

\section{Indigenous language loss and language use}

The loss of languages worldwide has been substantial over the past 200 years. Many linguists estimate that half to $90 \%$ of the world's languages will be moribund by the end of this century (Grenoble \& Whaley, 1998; Hale et al., 1992; Whalen \& Simons, 2012). Even so, there was little concentrated effort to retain and revitalize language among NA communities until recently, aided by the passage of the Native American Languages Act of 1990. Despite subsequent progress, NA languages are still rapidly losing speakers and the knowledge residing in their languages.

Language and culture are intertwined, and neither completely determines the other (McCarty \& Zepeda, 2010), but language use is a substantial indicator of cultural coherence. Many NA communities are engaged in the revival of language and culture (see examples Table 1), and raising the health of the community is often an explicit goal. For example, Stephanie Fielding (Mohegan Tribe, Council of Elders), states, "The Mohegan language program is more than a cultural effort, it is aimed at bringing our community together to improve its cohesion and health" (personal communication, 20 April 2016). There are indications that such efforts can be successful (e.g., Hinton, 2001:225), but the next section will survey published studies that more directly assess the effects of language maintenance (i.e., for first language (L1) speakers) and language revitalization (i.e., for second language (L2) learners).

\section{Existing studies}

Native health, from their own perspective, includes four domains: spiritual, mental, emotional and physical; a disruption in any part, is a loss in 'health' (Moss, 2015). More often there are several domains affected, so each must be considered in this discussion.

Spiritual life has always been key for American Indians. Intergenerational trauma or historical trauma has been termed as a 'spiritual injury', or 'soul wound'. A large driver of this trauma was the taking away of language (Duran et al., 1998). Prayers and 'medicine men' have utilized indigenous languages traditionally (Moss, 2000). In many cases it is the spirit that is being healed.

While the present survey focuses on the physical effects, mental and emotional factors certainly play a role in suicide. 
Table 1. Types of language learning environments and programs for Native American (NA) languages. L1/L2 indicates whether the language is a first language (L1) or learned later in life (L2) for the target population. Ratings of "poor" are often due to small numbers available.

\begin{tabular}{|c|c|c|c|c|}
\hline $\begin{array}{l}\text { Type of Environment/ } \\
\text { Program }\end{array}$ & Examples & L1/L2 & $\begin{array}{l}\text { Feasibility } \\
\text { for Use in } \\
\text { Retrospective } \\
\text { Research }\end{array}$ & $\begin{array}{l}\text { Feasibility } \\
\text { for Use in } \\
\text { Prospective } \\
\text { Research }\end{array}$ \\
\hline Learning from L1 parents & $\begin{array}{l}\text { Previously: About } 200 \text { US NA languages; } \\
\text { currently: about 30; www.ethnologue.org }\end{array}$ & L1 & Good & Poor \\
\hline $\begin{array}{l}\text { Regular gatherings of L1 } \\
\text { speakers }\end{array}$ & $\begin{array}{l}\text { Zuni (Moss, 2000); Wisconsin "keckīwak } \\
\text { elders" meetings }\end{array}$ & L1 & Moderate & Good \\
\hline Master/Apprentice & Cf. Hinton (2001) & $L 1+L 2$ & Poor & Poor \\
\hline $\begin{array}{l}\text { School instruction, } \\
\text { classroom }\end{array}$ & Cf. Cantoni (1996) & L2 & Moderate & Good \\
\hline Immersion schools & $\begin{array}{l}\text { Hawaiian (Wilson, 2012); Alutiiq } \\
\text { (www.alutiiqlanguage.org) }\end{array}$ & $L 2+L 1$ & Good & Good \\
\hline Learning from L2 parents & $\begin{array}{l}\text { Myaamia (www.myaamiacenter.org); } \\
\text { Wampanoag (www.wlrp.org) }\end{array}$ & $L 2+L 1$ & Poor & Moderate \\
\hline
\end{tabular}

Hallett et al. (2007) found the youth suicide rate for indigenous bands in British Columbia in which $50 \%$ of the community is conversationally fluent $(\mathrm{L} 1)$ to be $1 / 6^{\text {th }}$ that of less fluent bands. The language factor was predictive even when other correlated cultural factors were subtracted from the analysis.

On the physical side, another study found that the percentage of smokers in US Southwestern tribes, where indigenous languages are widely spoken, was only 14 percent as compared to 50 percent among Northern Plains tribes, where language use is sparse (Nez Henderson et al., 2005). A survey study in California (Hodge \& Nandy, 2011:797) found that those who could speak their ancestral language were more frequently classified in a (within-study defined) "good" wellness group (82.4\%) than were those who could not speak it (70.1\%). A survey of residents of the Hopi reservation found that language use was positively correlated with "practicing Hopi behaviors to keep healthy" (Coe et al., 2004:405). A recent study found that Canadian First Nations groups with greater cultural retention, as indexed by language use, had significantly lower rates of diabetes after factoring out socioeconomic factors (Oster et al., 2014). All of these studies combined L1 and L2 speakers.

In Australia, speaking an Aboriginal and/or Torres Strait Islander language was found to reduce several health risk factors such as excessive alcohol consumption (8\% vs. $18 \%$ for English monolinguals), illicit drug use (16\% vs. $26 \%$ ), and violence victimization (25\% vs. 37\%) (Australian Institute of Aboriginal and Torres Strait Islander Studies (AIATSIS), 2005:3). Those who spoke their heritage language were also found to have half the rate of "poor health" as those who had switched to English (Trewin \& Madden, 2005:95). Alcohol, violence and drug use (especially methamphetamines) are problematic in NA populations at rates exceeding the general US population (IHS, 2014:191).

One result based exclusively on L2 learners examined high school graduation rates, which are taken as a health indicator by the National Institutes of Health, in a Hawaiian language immersion school. The Nāwahī program in Hawaii has a $100 \%$ graduation rate (Wilson, 2012), compared to $70 \%$ for standard schools (Kamehameha Schools, 2009).

\section{Why focus on language?}

Language transmission is a particularly effective means of reinforcing culture and has the benefit of integrating most cultural and communal activities. Language is also an extremely efficient means of establishing membership or inclusion in a community. Studies that might disentangle language and culture are possible, but the approach argued for here takes it as a given that language is the most efficient means of transmitting, maintaining, and even reviving culture.

There are different kinds of environments and programs for language learning and use (Table 1). Evaluation can be a challenge, whether the study is retrospective or prospective, due to large differences in specifics and small numbers in many cases. Census data can, with limitations, add to the results. Prospective studies could compare such health measures as absentee rates from school or changes in the Youth Risk Behavior Surveillance System (YRBSS; Centers for Disease Control and Prevention, 2004). While indirect, these measures can be obtained for all children, allowing larger cohorts than would be possible if only eventual negative outcomes were measured.

The main recommendation suggested by these studies, then, is that language programs prospectively include assessment of health outcomes along with the core of the program (see also Marmion et al., 2014:46). In this way, samples across the wide variety of programs can be compared, with the expectation that those with the most positive health outcomes can be replicated in other programs. Comparisons, both in effectiveness and cost, to standard health programs are also needed, given that language programs are typically less expensive than many other types of programs. 


\section{Conclusion}

Language programs in NA communities hold the promise of improving the mental and physical health of those who participate in them. All generations seem able to take advantage of this possibility. Data exist on palliative effects of use of a Native language and/or cultural practices on smoking (Nez Henderson et al., 2005), suicide rates (Hallett et al., 2007) and alcohol (Torres Stone et al., 2006; Whitbeck et al., 2004) and substance abuse (First Peoples' Heritage Language and Culture Council, 2012:213), but many more issues are likely to be evident as more data are collected. A return to native spirituality has been shown to improve treatment results (Berry et al., 2012; Gone \& Calf Looking, 2015), an effect that could be expected to increase with inclusion of the ancestral language. As Tulloch et al. (2013) point out, the many informal programs that have appeared recently are not well studied and may require novel methodologies.

The Endangered Language Fund has launched a program called Healing Through Language to facilitate the support and assessment of language programs throughout Native America (www.healingthroughlanguage.org). Communities throughout the US and elsewhere have started language programs with a wide range of models. Because this one type of program can, apparently, lead to positive outcomes in so many areas, we would expect to find a substantial return in health benefits on investment in language programs in Native America.
Speaking an indigenous language in and of itself may not be solely responsible for improved health status; rather, community validation of the indigenous knowledge system, community-driven tribal education, comprehending indigenous medicine, and youth empowerment through language and culture identity formation all play significant roles in the ability of a minority language to thrive and for the community to experience healthy outcomes from the collective effort.

\section{Author contributions}

All authors reviewed the literature and provided input to and reviewed all drafts of the manuscript.

\section{Competing interests}

No competing interests were disclosed.

\section{Grant information}

The author(s) declared that no grants were involved in supporting this work.

\section{Acknowledgements}

Helpful comments were provided by Monica Macaulay, Alice Taff, Susan Penfield and Linda Mayes.
Anderson I, Crengle S, Kamaka ML, et al.: Indigenous health in Australia, New Zealand, and the Pacific. Lancet. 2006; 367(9524): 1775-1785.

PubMed Abstract | Publisher Full Text

Australian Institute of Aboriginal and Torres Strait Islander Studies (AIATSIS):

National Indigenous Languages Survey Report 2005. 2005.

Reference Source

Berkman ND, Sheridan SL, Donahue KE, et al.: Low health literacy and health outcomes: an updated systematic review. Ann Intern Med. 2011; 155(2): 97-107.

PubMed Abstract | Publisher Full Text

Berry SL, Crowe TP, Deane FP, et al.: Growth and empowerment for Indigenous Australians in substance abuse treatment. Int J Ment Health Addict. 2012; 10(6): 970-983.

Publisher Full Text

Brave Heart MY, DeBruyn LM: The American Indian Holocaust: healing historical unresolved grief. Am Indian Alsk Native Ment Health Res. 1998; 8(2): $60-82$.

PubMed Abstract | Publisher Full Text

Cantoni $\mathrm{G}(\mathrm{Ed}$ ): : Stabilizing indigenous languages. Flagstaff, AZ: Northern Arizona University Press. 1996.

Reference Source

Centers for Disease Control and Prevention: Methodology of the youth risk behavior surveillance system. MMWR Surveill Summ. 2004; 54(RR-12): 1-13. Reference Source

Coe K, Attakai A, Papenfuss M, et al.: Traditionalism and its relationship to disease risk and protective behaviors of women living on the Hopi reservation. Health Care Women Int. 2004; 25(5): 391-410.

PubMed Abstract | Publisher Full Tex

Duran B, Duran E, Brave Heart MYH: The trauma of history. In R. Thornton (Ed.), Studying Native America: Problems and perspectives. Madison, WI: University of Wisconsin Press. 1998; 60-78.

Reference Source

Dussias AM: Waging war with words: Native Americans' continuing struggle against the suppression of their languages. Ohio State Law Journal. 1999;

\section{0(3): 901-993}

Reference Source

Firestone M, Smylie J, Maracle S, et al:: Unmasking health determinants and health outcomes for urban First Nations using respondent-driven sampling. BMJ Open. 2014; 4(7): e004978.

PubMed Abstract | Publisher Full Text | Free Full Text

First Peoples' Heritage Language and Culture Council: Report on the Status of B.C. First Nations Languages 2010. Brentwood Bay, B.C.: First Peoples' Heritage, Language and Culture Council. 2012.

Reference Source

Frohlich KL, Ross N, Richmond C: Health disparities in Canada today: some evidence and a theoretical framework. Health Policy. 2006; 79(2-3): 132-143. PubMed Abstract | Publisher Full Text

Gone JP, Calf Looking PE: The Blackfeet Indian culture camp: Auditioning an alternative indigenous treatment for substance use disorders. Psychol Serv. 2015; 12(2): 83-91.

PubMed Abstract | Publisher Full Text

Gracey M, King M: Indigenous health part 1: determinants and disease patterns. Lancet. 2009; 374(9683): 65-75.

PubMed Abstract | Publisher Full Text

Grenoble LA, Whaley LJ (Eds.): Endangered languages: Language loss and community response. Cambridge: Cambridge University Press. 1998.

Reference Source

Hale K, Krauss M, Watahomigie LJ, et al.: Endangered languages. Language. 1992; 68(1): 1-42.

Publisher Full Text

Hallett D, Chandler MJ, Lalonde CE: Aboriginal language knowledge and youth suicide. Cognitive Development. 2007; 22(3): 392-399.

Publisher Full Text

Hinton L: The master-apprentice language learning program. In L. Hinton \& K. Hale (Eds.), The Green Book of language revitalization in practice. London:

Academic. 2001; 217-226.

Publisher Full Text

Hodge FS, Nandy K: Predictors of wellness and American Indians. J Health 
Care Poor Underserved. 2011; 22(3): 791-803.

PubMed Abstract | Publisher Full Text | Free Full Text

Indian Health Service: Trends in Indian health: 2014 edition. Rockville, MD: Indian Health Service. 2014.

Reference Source

Kamehameha Schools: Native Hawaiian educational assessment update 2009: A supplement to Ka Huaka'i 2005. Honolulu: Kamehameha Schools, Research

and Evaluation Division. 2009.

Reference Source

King M, Smith A, Gracey M: Indigenous health part 2: the underlying causes of the health gap. Lancet. 2009; 374(9683): 76-85.

PubMed Abstract | Publisher Full Text

Les Whitbeck B, Chen X, Hoyt DR, et al.: Discrimination, historical loss and enculturation: culturally specific risk and resiliency factors for alcohol abuse among American Indians. J Stud Alcohol. 2004; 65(4): 409-418.

PubMed Abstract | Publisher Full Text

Marmion D, Obata K, Troy J: Community, identity, wellbeing: The report of the Second National Indigenous Languages Survey. Canberra: Australian Institute of Aboriginal and Torres Strait Islander Studies (AIATSIS). 2014.

Reference Source

McCarty TL, Zepeda O: Native Americans. In J. A. Fishman \& O. García (Eds.) Handbook of language and ethnic identity. (2nd ed) Oxford; New York: Oxford University Press. 2010; 323-339.

Moss MP: Zuni elders: Ethnography of American Indian aging. (Ph.D. dissertation), University of Texas School of Nursing at Houston. 2000.

Reference Source

Moss MP: American Indian health and nursing. New York: Springer. 2015 Reference Source

Nez Henderson $\mathrm{P}$, Jacobsen C, Beals J, et al:: Correlates of cigarette smoking among selected Southwest and Northern plains tribal groups: the Al-SUPERPFP Study. Am J Public Health. 2005; 95(5): 867-872.

PubMed Abstract | Publisher Full Text | Free Full Text

Oster RT, Grier A, Lightning R, et al:: Cultural continuity, traditional Indigenous

language, and diabetes in Alberta First Nations: a mixed methods study. Int $J$
Equity Health. 2014; 13(92): 1-11.

PubMed Abstract | Publisher Full Text | Free Full Text

Pan American Health Organization: Equity and health: Views from the Pan

American Sanitary Bureau. Washington, DC: PAHO. 2001.

Reference Source

Sotero MM: A conceptual model of historical trauma: Implications for public health practice and research. $J$ Health Dispar Res Pract. 2006; 1(1):

93-108.

Reference Source

Stone RA, Whitbeck LB, Chen X, et al.: Traditional practices, traditional spirituality, and alcohol cessation among American Indians. J Stud Alcohol. 2006; 67(2): 236-244.

PubMed Abstract | Publisher Full Tex

Trewin D, Madden R: The health and welfare of Australia's Aboriginal and Torres Strait Islander peoples. Canberra: Australian Bureau of Statistics. 2005. Reference Source

Tulloch S, Kusugak A, Uluqsi G, et al.: Stitching together literacy, culture \& wellbeing: The potential of non-formal learning programs. Northern Public Affairs. 2013; 2(2): 28-32.

Reference Source

U.S. Commission on Civil Rights: Broken promises: Evaluating the Native American health care system. Washington, DC: U.S. Commission on Civil Rights. 2004; 1-155.

Reference Source

Wang WS, Minett JW: The invasion of language: emergence, change and death Trends Ecol Evol 2005; 20(5): $263-2$

PubMed Abstract | Publisher Full Tex

Whalen DH, Simons GF: Endangered language families. Language. 2012; 88(1): 155-173.

Publisher Full Text

Wilson WPH: USDE violations of NALA and the testing boycott at Nāwahīokalani'ōpu'u School. J Am Indian Educ. 2012; 51(3): 30-45.

Reference Source 


\title{
Open Peer Review
}

\section{Current Peer Review Status: ? ?}

\section{Version 1}

Reviewer Report 21 September 2016

https://doi.org/10.5256/f1000research.9315.r14157

(C) 2016 Clark T. This is an open access peer review report distributed under the terms of the Creative Commons Attribution License, which permits unrestricted use, distribution, and reproduction in any medium, provided the original work is properly cited.

\section{Terryann Coralie Clark}

School of Nursing, University of Auckland, Auckland, New Zealand

Thank you for the opportunity to review this review.

I think this article is of significant importance for indigenous peoples and links ancestral wisdom with some evidence. I do think that the article is weak in some areas:

\begin{abstract}
I think the abstract could stronger. It is unclear what you conclude and what evidence you have. e.g. Evidence suggests that language maintenance can be associated with improved health, social and education outcomes for American Indians an indigenous populations. This is evidenced by ...

\section{Introduction}

The links between language and well-being need to be stronger. Need more evidence that language is associated with well-being. What is the theories about how language and cultural maintenance, cultural connection improve outcomes? Think your paper would be stronger if it maintained its international literature focus - there is more evidence if you use Australia, NZ and other indigenous people. Need to state what the purpose of the paper is. What you intend to review.
\end{abstract}

\section{Health status}

This section could be stronger. There is a lot of evidence about poor health among indigenous peoples. What is health from an indigenous perspective?

\section{Indigenous language and loss}

Talking about 'language loss' suggests that it was somehow accidental. Language was a purposeful way to colonise indigenous peoples.

\section{Existing studies (Evidence to support language revitalisation?)}

Not sure about this heading - what is meant by existing studies? Watch causation language - these are associations e.g. "speaking an indigenous language was found to reduce several health risks 
(p.3) " - should read speaking and indigenous language was associated with reduced risk.

\section{Why focus on language?}

Think this section should come earlier - what is the theory that language is a powerful protective factor?

The table provided is unrelated to the content and doesn't add much. Unsure what this is for - link to purpose statement at the beginning. e.g. The purpose of this review is to review the literature about the importance of language to indigenous well-being and identify the programmes and data available that might be evaluated? Need more on this as it is not clear from your review.

\section{Conclusions}

Should be more focused.

Overall - I think this is useful information for indigenous peoples but it requires a significant restructure and rewrite to make it cohesive.

Competing Interests: No competing interests were disclosed.

\section{I confirm that I have read this submission and believe that I have an appropriate level of expertise to confirm that it is of an acceptable scientific standard, however I have significant reservations, as outlined above.}

Reviewer Report 07 June 2016

https://doi.org/10.5256/f1000research.9315.r14162

(C) 2016 Oster R. This is an open access peer review report distributed under the terms of the Creative Commons Attribution License, which permits unrestricted use, distribution, and reproduction in any medium, provided the original work is properly cited.

\section{Richard T Oster \\ Department of Medicine, University of Alberta, Edmonton, AB, Canada}

This is a timely and important article. Indigenous peoples continue to voice the importance of culture and language revitalization for their well-being. As a result, more and more research is being conducted linking language and health in Indigenous populations. A review or summary of that work is needed, hence the current article. I commend the authors for undertaking this vital task. Generally, the article is well written and informative. However, I found that some sections were not thoroughly explored and the authors would do well by deepening their literature review and expanding on their ideas. My comments are as follows:

1. I suggest the authors capitalize the term "Indigenous" throughout the article. 
2. Abstract, third sentence: it is not clear what the authors mean by "communities" here. Also, compared to what population is their "lowered health status"?

3. Abstract: it would be useful to add a sentence on how language revitalization is thought to improve health.

4. Introduction: the authors state that this current article is a survey. This is a bit confusing. The authors should be clear on what type of article this is. It is not a quantitative survey, systematic review, meta-analysis, review, or literature search. As the article is now, an "opinion piece" seems more appropriate. However, I'm hoping that the authors can expand on many of their ideas and explore the known literature further. In which case, the article may be appropriately termed a "review".

5. Introduction, paragraph 3, last sentence: I'm not sure that the references cited support the claim being made that language shifts have caused the health deficits we see today among Indigenous populations. Perhaps the authors can rework this sentence.

6. Health status: this is one of the sections that seems lacking in its scope. Perhaps the authors can expand and describe some of the major health disparities among Indigenous populations. Some epidemiological data would be helpful to the reader to understand the scope of the disparities.

7. Indigenous language loss and language use: it would be helpful to the reader if the authors provided examples of some of the Indigenous languages. What are some of the major Indigenous languages worldwide? How many are there? How many have been lost? It would also be helpful if the authors provided some data on how much Indigenous languages are being spoken today around the world and in North America.

8. Existing studies and why focus on language sections: These sections in particular need to be expanded upon. Are the authors able to conduct a formal literature search? Perhaps with keywords? Also, the authors may want to explore and include other literature that has explored the relationship between language/culture and emotional/mental health. The extensive writings of Laurence Kirmayer come to mind as a good place to start. What is explicitly missing from this article is the how piece... How does language revitalization lead to better health? Is it due to enhanced sense of identity (as Chandler and Lalonde argue)? Enhanced spiritual health? Enhanced sense of community/belonging? The provision of strong role models that teach the language? Protection from early life traumas? There is also an entire field of neurological research that has looked at how learning multiple languages can impact the brain and health. The authors would do well to explore these different areas and give the reader an idea on the how. Even looking into some of the qualitative research with Indigenous peoples suffering from some of the major health problems that Indigenous populations face (e.g. diabetes) would be beneficial as often language/culture is brought up as a key determinant of health in these studies. Moreover, has there been research that has shown not shown a relationship between language and health? Lastly, second paragraph, last sentence: Has there been work done that specifically examined language loss and sense of spiritual well-being? 
9. I was pleased that the authors recommend that future studies aimed at language revitalization include assessments of health outcomes. Perhaps the authors could expand on what these health assessments may look like? What should be measured and how?

10. Conclusion: It would make more sense perhaps to include and expand upon the Berry 2012, Gone 2015, and Tullouch 2013 references in the "existing studies" or "why focus on language" sections.

11. Last paragraph of conclusion: the ideas presented in this paragraph seem to come out of nowhere as they have not been discussed earlier in the article. Again, the authors would do well to really spend some time reading and then summarizing in the "existing studies" or "why focus on language" sections the known literature on how and why language revitalization may lead to improved health. These sections are the place (as opposed to the conclusion) to introduce and describe in-depth the other contributors related to speaking an Indigenous language that may be responsible for improved health status.

Competing Interests: No competing interests were disclosed.

I confirm that I have read this submission and believe that I have an appropriate level of expertise to confirm that it is of an acceptable scientific standard, however I have significant reservations, as outlined above.

\section{Comments on this article}

\section{Version 1}

Reader Comment 10 May 2016

Nick Thieberger, University of Melbourne, Australia

Some additional references that may be useful:

Bialystok, E., Craik, F. \& G. Luk, G. 2012. Bilingualism: consequences for mind and brain. Trends in Cognitive Sciences 16(4): 240-250.

Biddle, N. and H. Swee. 2012. 'The Relationship Between Wellbeing and Indigenous Land, Language and Culture in Australia'. Australian Geographer 43: 215-232.

Waldram, James B. 2009. The persistence of traditional medicine in urban areas: the case of Canada's

Indians. Am Indian Alsk Native Ment Health Res. 1990 4(1):9-29.

Competing Interests: No competing interests were disclosed. 
The benefits of publishing with F1000Research:

- Your article is published within days, with no editorial bias

- You can publish traditional articles, null/negative results, case reports, data notes and more

- The peer review process is transparent and collaborative

- Your article is indexed in PubMed after passing peer review

- Dedicated customer support at every stage

For pre-submission enquiries, contact research@f1000.com 